\title{
Investigation Of Predictable And Numerical Pulse Width Modulation Control Scheme For BLDC Motor Drive System
}

\section{K. Bhaskar ${ }^{a}$, K. Sudharshan ${ }^{\mathrm{b}}$}

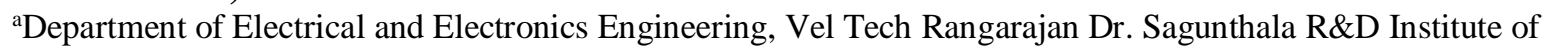
Science and Technology, Avadi, Chennai, India. E-mail: bhaskark@ veltech.edu.in

${ }^{\mathrm{b}}$ Department of Electrical and Electronics Engineering, Vel Tech Rangarajan Dr. Sagunthala R\&D Institute of Science and Technology, Avadi, Chennai, India. E-mail: sudharshan@gmail.com

Article History: Received: 11 January 2021; Accepted: 27 February 2021; Published online: 5 April 2021

Abstract: In this paper shows check the traditional, CPWM (computerized pulse width modulation) regulator combine for control of speed by the automatic group the Brushless dc (BLDC) motor, from these strategies, pursue from CPWM speed control system, the main distinction is in the regulator part. Unique drive framework comprises of a steady Proportional Integrator controller and different has an advanced controller. This paper remembers conversation for the execution of both the strategies and their exhibitions are thought about.

Keywords: Proportional Integrator (PI) Computerized Pulse Width Modulation (CPWM), Brushless DC (BLDC), Voltage Source Inverter (VSI) Control Calculation, Field-programmable Door Clusters (FPGAs).

\section{Introduction}

Because of the favourable circumstances like advanced proficiency and a smaller amount of support ended traditional DC and Induction motors, the BRUSHLESS DC motors take various applications for business and private areas. The fundamental inconveniences similar greater expense and multifaceted control calculation confine postulations drive low and intermediate force applications like a sensor or sensorless strategies may be utilized to regulator the brushless DC motor, the benefit of sensorless brushless DC motor control is general expenses to be decreased yet to bring about the awareness-confusing control calculation. So, cost-proficient, yet compelling brushless DC motor controller is energized [1]

The regulator of the motor can be accomplished by directing the adjustment of the converter(DC-DC) and this strategy determine to build the general expense for the system. Another procedure is to be controlled by the leg switches in the inverter, in this manner the normal voltage to be applied over by the meandering of the motor, without altering the direct current (DC) bus voltage, the control of the motor is accomplished by the PWM strategy remains utilized for actualizing of both hysteresis current controller and PWM scheme and it should be combined through constant control and hypothesis are ordinarily utilized for control of the Brushless DC motor drive the hysteresis current control has preferable execution over PWM control [3].

Be that as it may, the speed control should be calculated is intricate and essentially growing current senors. When contrasted with PWM control the hysteresis current control scheme should remain possible utilizing solitary current sensor [4] however another time bring about complex speed control calculation.

\section{Block Diagram of BLDC System}

The Schematic diagram of BLDC system shown in Figure 1.

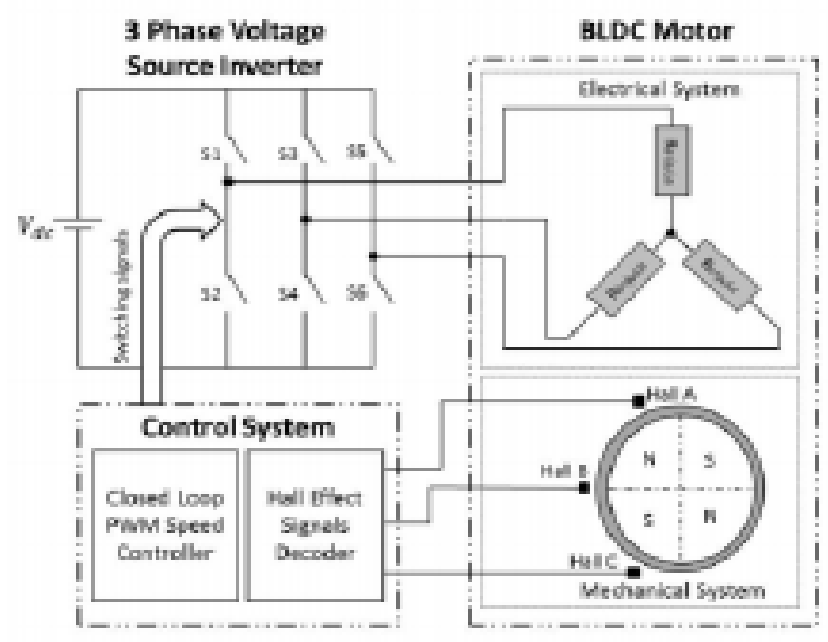

Figure 1. Drive System for Brushless DC Motor 
In the review paper for in cooperation of both control techniques, Brushless DC motor commutation depends upon three intrinsic Hall Effect sensors the Automatic commuting of $120^{\circ}$ depends upon the estimations of the Hall Effect sensors, the Six segments commuting strategy is to be utilized to change the three-stage Voltage source inverter (VSI) in six-segment replacing arrangements. Table one shows the automated replacement for the circular pivot. Just two Brushless DC motor stage windings are invigorated for respectively each exchanging arrangement over inverter switches one is from the higher sideways to additional from the subordinate side, each stage either adjustment is leading by $120^{\circ}$ electrical.

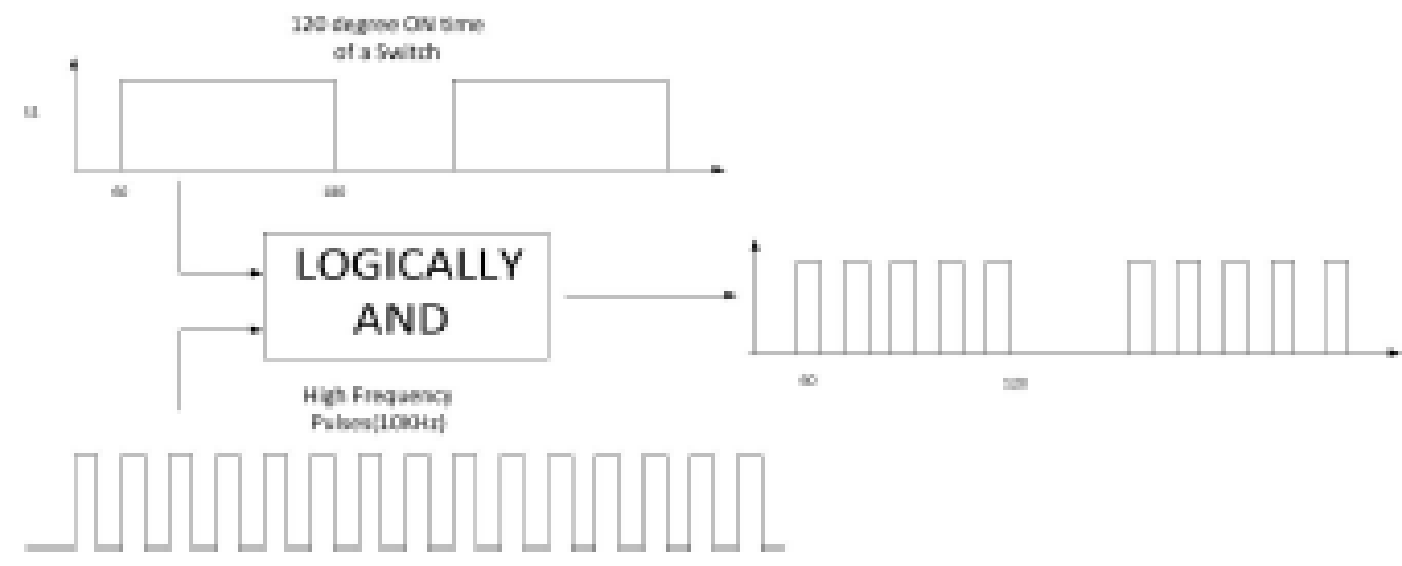

Figure 2. Generation of Pulsations for Switching

Table I. In Clockwise Direction Interpreting Rules of Hall Effect Signals

\begin{tabular}{llllll}
\hline Division No & Rotor angle (Electrical Degree) & HA & HB & HC & Switches are performing \\
\hline 1 & $35-100$ & 1 & 0 & 1 & $\mathrm{~S}_{1} \mathrm{~S}_{4}$ \\
6 & $101-150$ & 1 & 0 & 0 & $\mathrm{~S}_{1} \mathrm{~S}_{4}$ \\
5 & $155-220$ & 1 & 1 & 0 & $\mathrm{~S}_{1} \mathrm{~S}_{4}$ \\
4 & $212-260$ & 0 & 1 & 0 & $\mathrm{~S}_{1} \mathrm{~S}_{4}$ \\
3 & $265-330$ & 0 & 1 & 1 & $\mathrm{~S}_{1} \mathrm{~S}_{4}$ \\
2 & $330-35$ & 0 & 0 & 1 & $\mathrm{~S}_{1} \mathrm{~S}_{4}$ \\
\hline
\end{tabular}

For accomplish the control of the speed by high recurrence CPWM gesture is legitimately and to the transfer the time of each switch. Thusly exchanging heartbeats are created, appeared as shown in Figure 2 These be able to be applied in the direction of the entire six leg switches either upper leg switches or lower leg switches. Straight forward Pulse Width Modulation stage procedure is to be utilized by looking at situation esteem (obligation) with great recurrence of $10 \mathrm{kiloHz}$ sawtooth waveforms this strategy recurrence stays consistent yet the width of the beat will shift as indicated by reference esteem, which brings about speed variety. To acquire shut circle speed control of the motor roughly criticism should be occupied. In this review article for mutually speed control plans genuine motor control the speed of the criticism which can remain evaluated in two different ways one is as of rotor place sensors, the other route is the visual encoder. The previous technique gives small precision than the delayed one. In this review article, the speed evaluation can be determined to utilize visual encoder.

\section{Conservative CPWM Control}

The Schematic Figure 2 designed for a closed-loop CPWM governor design utilizing Proportional and integral(PI) controller appears in Figure 3 the DC interface electrical energy can be acquired so, produce of three stages in DBR. The real speediness of the motor can be evaluated on or after the visual encoder. Automatic substitution finished by unravelling the qualities as of the location of the sensors. Praportional and integral(PI) controller comprise of equally corresponding (P), essential (I) controller are utilized in equivalent. Contribution to the organiser is the direction of the running speed and actual speed, The error in the speed is assumed to Praportional, integral(PI).

The produce of mutually the controllers are included to produce another obligation cyclen ratio. In the PWM creator, the responsibility cycle is to be contrasted and extreme recurrence (10 kilo $\mathrm{Hz})$ sawtooth waveform intended for the stage of the PWM flags and coherently and with the automatic commutated exchanging motions. 
The created exchanging strokes is given to the IGBT system adjustments of the system (inverter) to empower to the twisting for a turn.

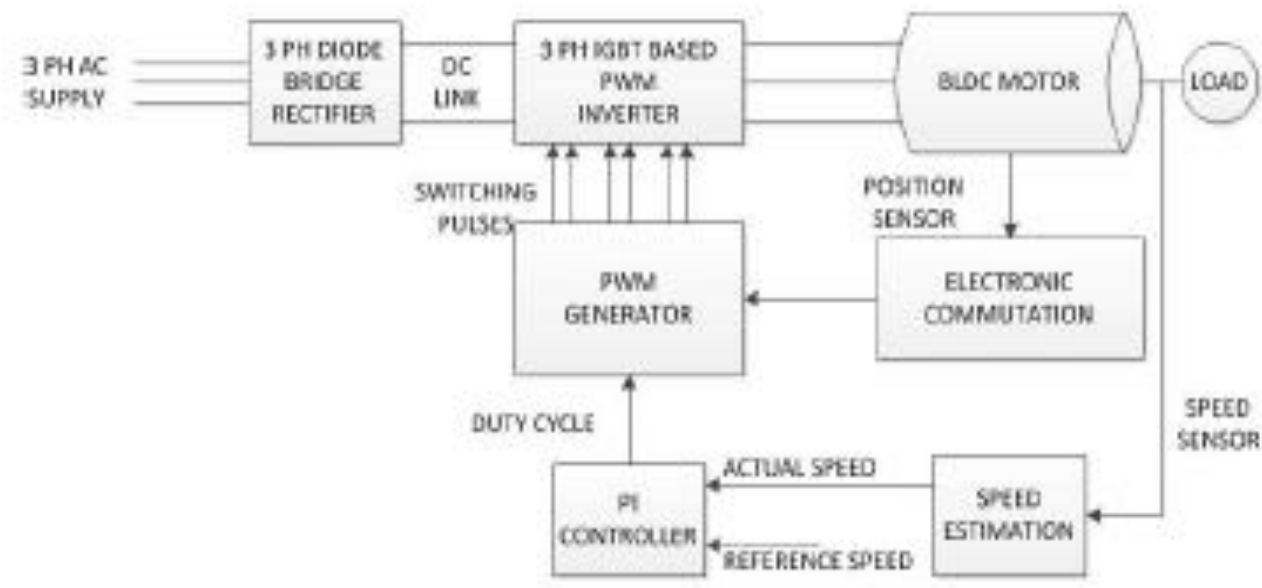

Figure 3. Regular CPWM (Computerized Pulse Width Modulation) Control Design Utilizing a PI Controller

\section{Digital CPWM Control}

The Schematic Figure designed for closed-loop CPWM control design exhausting with the digital controller as shown in Figure 4.

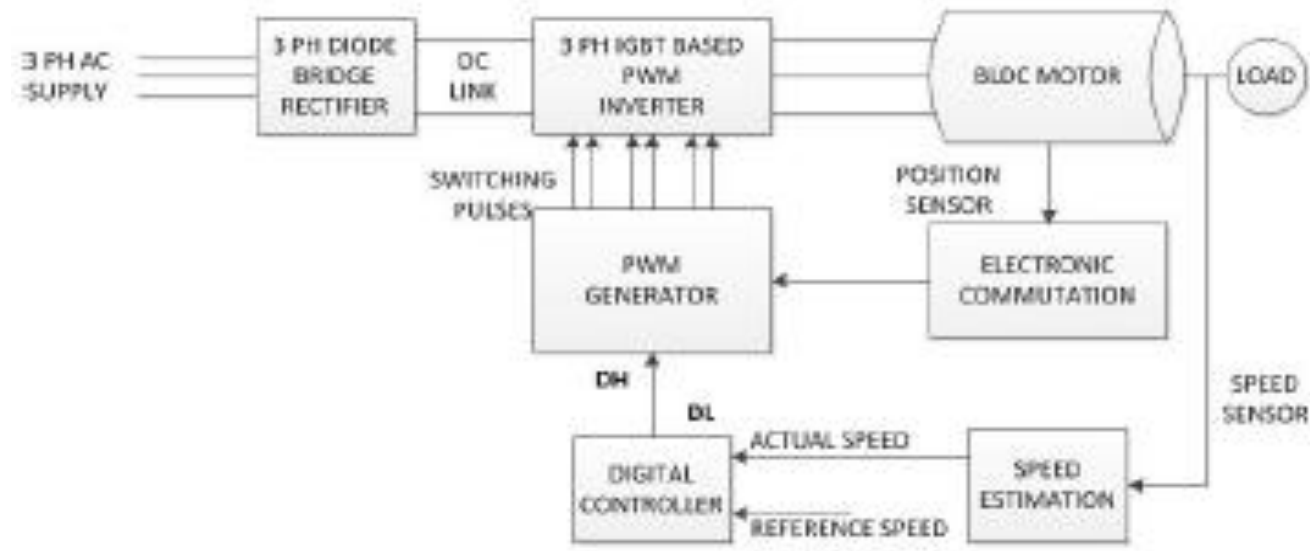

Figure 4. CPWM (Computerized Pulse Width Modulation) Control Scheme

Contrasting with regular Pulse Width Modulation control plot just distinction in the controller part. The produce of the advanced regulator has just 2 qualities, small value termed as obligation low (DL), additional is extreme worth named by obligation high $(\mathrm{DH})$. Each worth determination to be picked in turn moreover less or more, that is the reason for preserved in advanced controller, the speed controlof the machine occurs moved through rotating exchanging among less and more obligation, which can be predefined.

In this strategy the Ordinal regulator extravagance the Brushless DC engine is an advanced framework. Stream outline portraying the computerized PWM control plot appears in the Figure 4 Contribution for the computerized speed (Wa) and orientation speed (Wr) and Crisscross climate which is more noteworthy if $\mathrm{Wr}>$ Wa. Select obligation high $(\mathrm{DH})$ to raise the speed, then contrasted and extreme recurrence 10kilo Hz sawtooth waveform designed for the age of the pulse width modulation flags and is legitimately and with the automatic commutated exchanging indications on the off chance that $\mathrm{Wr}<\mathrm{Wa}$, at that point select short obligation (DL) to lessen the speediness. So the control speed is accomplished by substituting exchanging among obligation high (DH) and obligation low (DL), these are predefined. The primary obstacle of the advanced controller pulse width modulation plot is speediness swell even inconsistent state moreover. In the event of Praportional Integration controller, the yield can consume any worth, might be a consistent, expanding or a diminishing one, yet on account of electronic regulator, it is moreover a re-imagined small or extreme worth. 


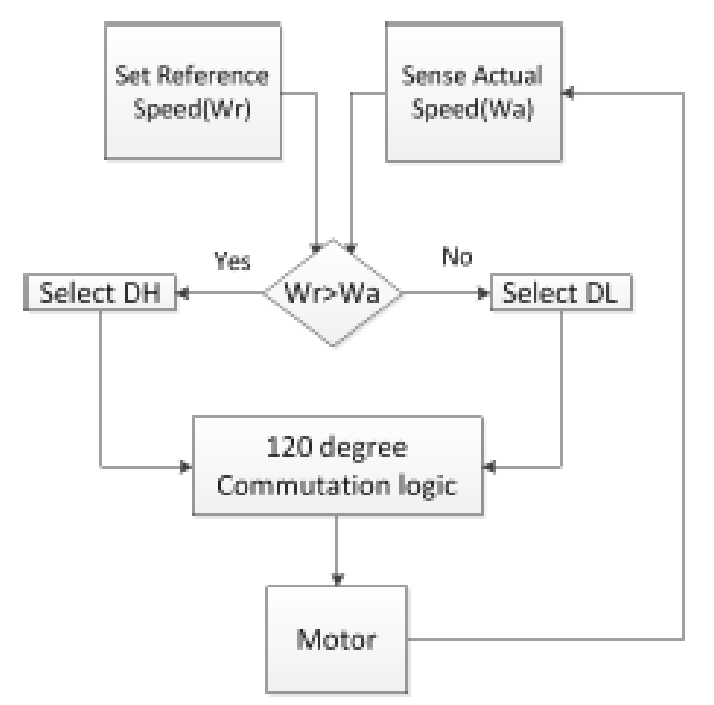

Figure 5. Digital Pulse Width Modulation Flow Chart

\section{Simulation Results}

The Brushless DC drive framework is rehashed by utilizing MATLAB/Simulink age programming. The structure is reproduced with a BLDC motor model gave in power library of Simulink. The drive structure framework is replicated for normally control create. The substance respect likes relative steady $\mathrm{Kp}$, key solid $\mathrm{Ki}$, Small duty cycle DL, and high responsibility cycle DH is begun by experimentation procedure. The Brushless DC engine confinements have shown up in Table II. Figure 6 to Figure 14 shows the reenactment Figure 6 and Figure 7 shows the speed reaction of $1800 \mathrm{rpm}$ at an information DC voltage of $300 \mathrm{~V}$ when the value and surveyed upset of $3.6 \mathrm{Nm}$. Relating power, stage present and back emf are in like way plotted in Figure 8 to Figure 11.

Table II. Brush Less Dc Motor Parameters

\begin{tabular}{|l|l|}
\hline Make and model & BSM33C-3178 MHQ \\
\hline Power reating & $1 \mathrm{hp}$ \\
\hline Rated Speed & $1800 \mathrm{rpm}$ \\
\hline Rated voltage & $320 \mathrm{~V}$ \\
\hline No. of poles & 4 \\
\hline Maximum speed & $7500 \mathrm{rpm}$ \\
\hline Resistance/ phase (R) & $4.36 \Omega$ \\
\hline Inductance/ phase (L) & $16.483 \mathrm{mH}$ \\
\hline Inertia of the Rotor & $0.00536 \mathrm{~kg}-\mathrm{m}^{2}$ \\
\hline
\end{tabular}

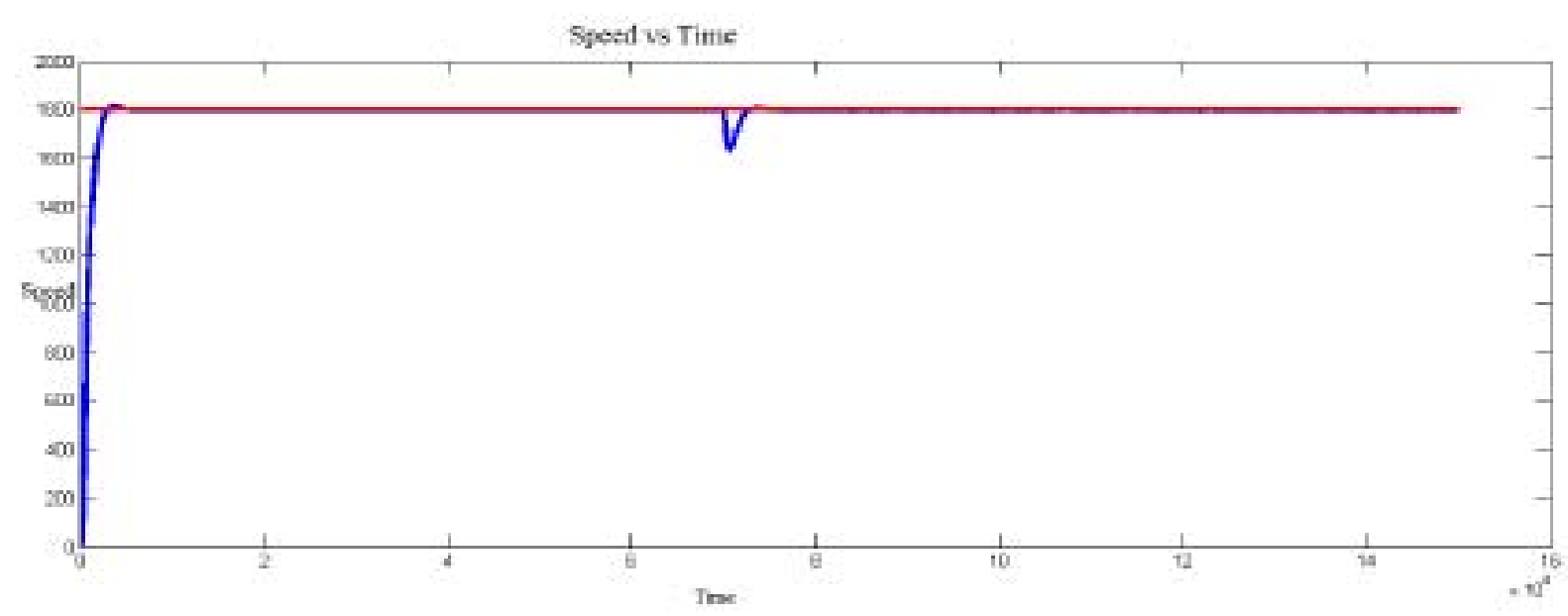

Figure 6. Response Speed Using PI Controller (for $\mathrm{T}=3.8 \mathrm{Nm}$ at $0.0 \mathrm{sec}$ ) 


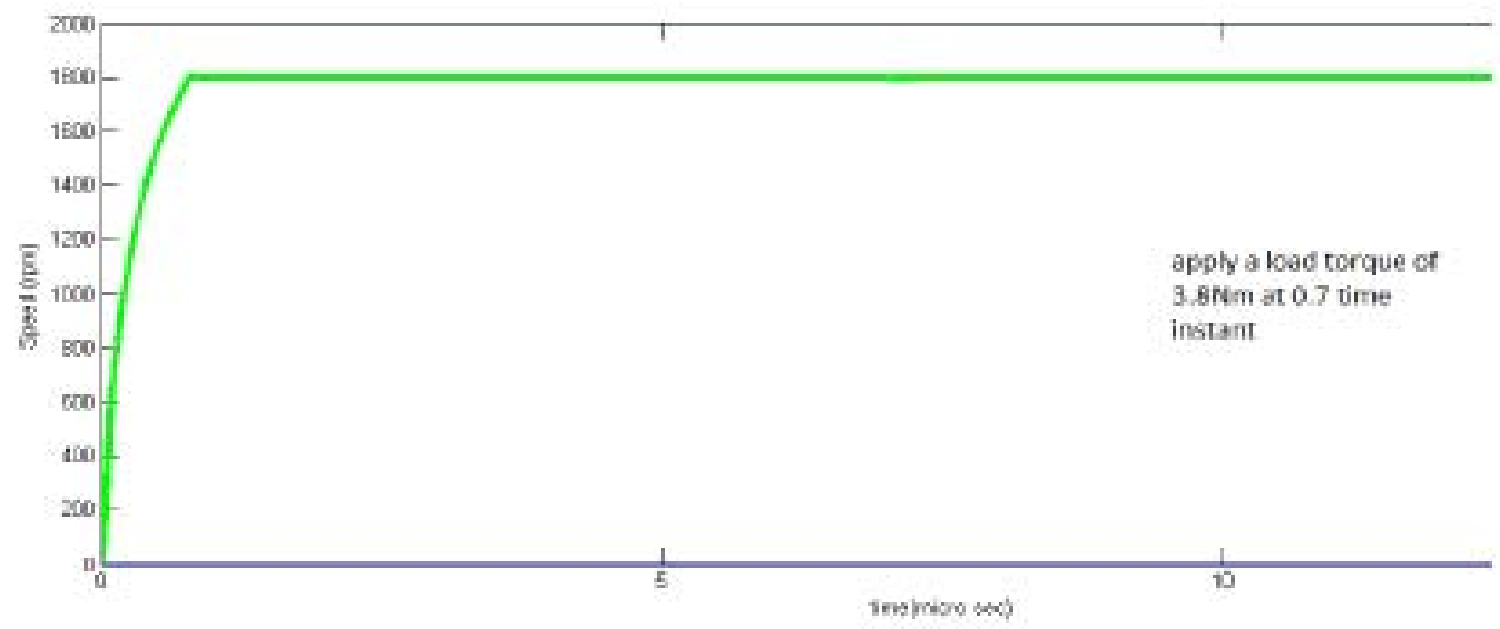

Figure 7. Speed Response Using a Digital Controller for T $(3.8 \mathrm{Nm})$ at $0.0 \mathrm{sec}$

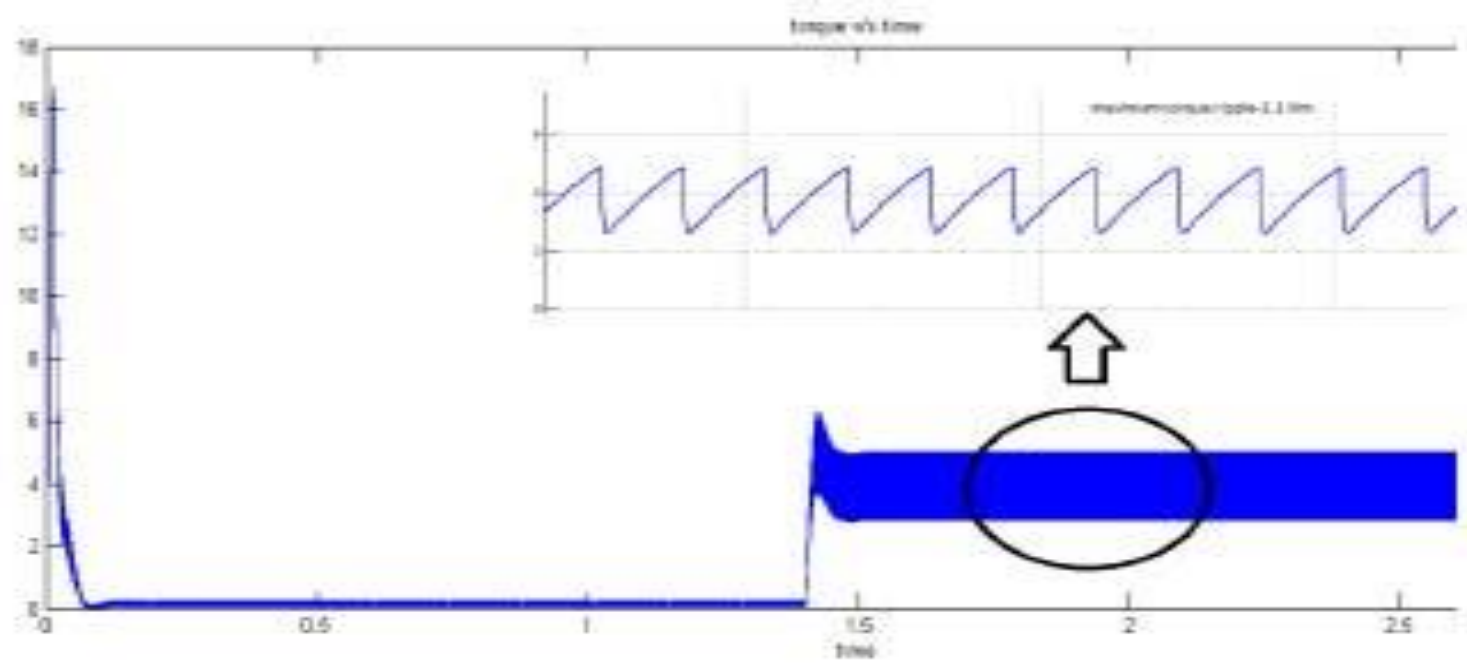

Figure 8. Torque T Using a PI Controller

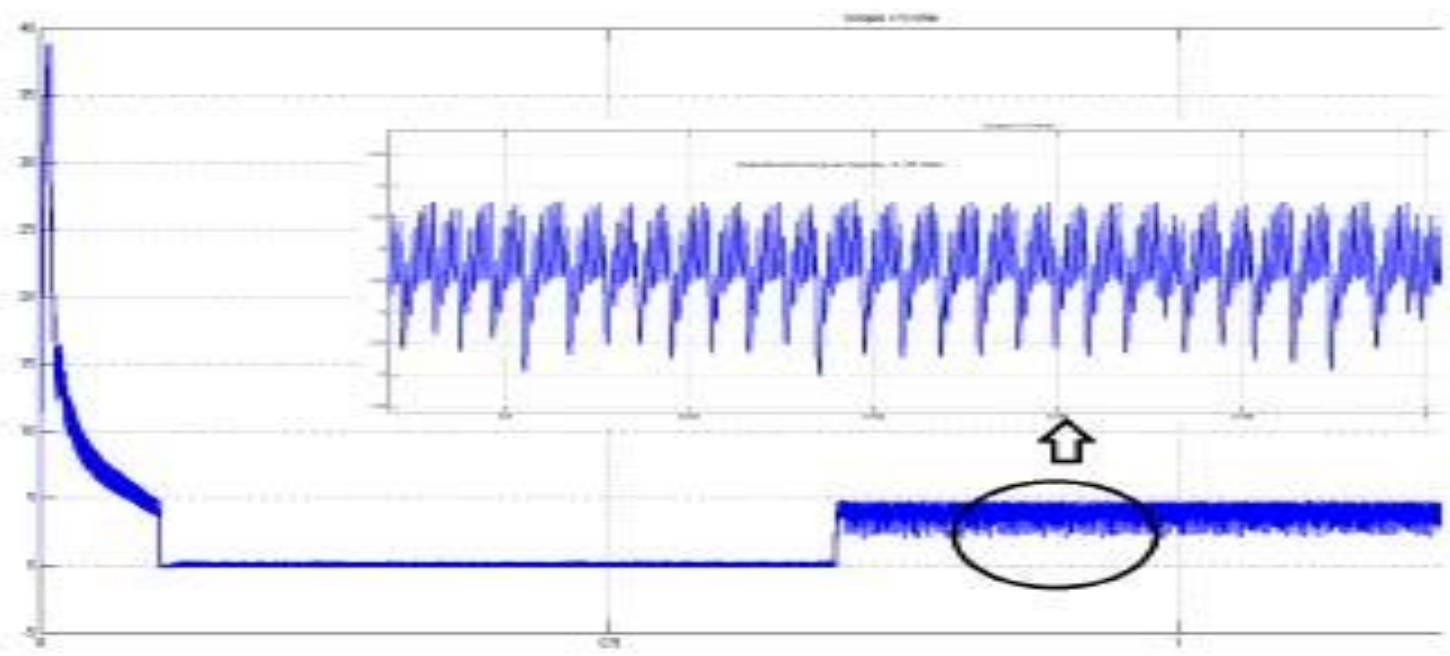

Figure 9. Torque T Using a Digital Controller

Figure 10 and Figure 11 speaks to the stage current and back emf of stage a. The improved current waveform is for regular control utilizing Praportional Integration (PI) than an advanced controller. 

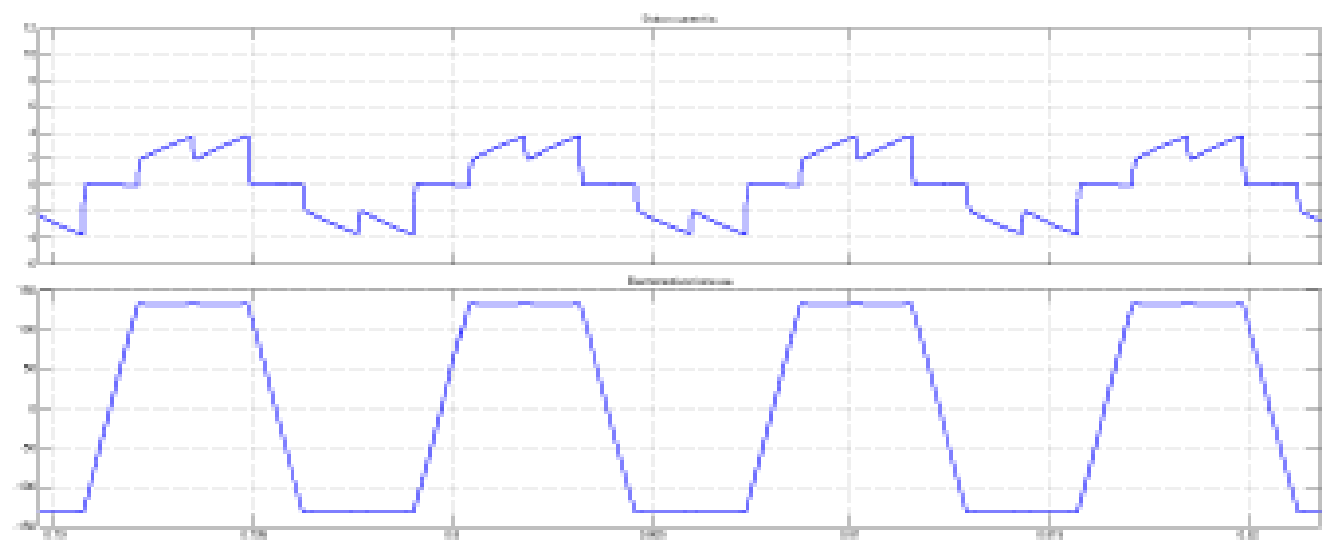

Figure 10. Phase Current, Phase EMF of a Valued Load by Using Praportional Integration Controller (PI)
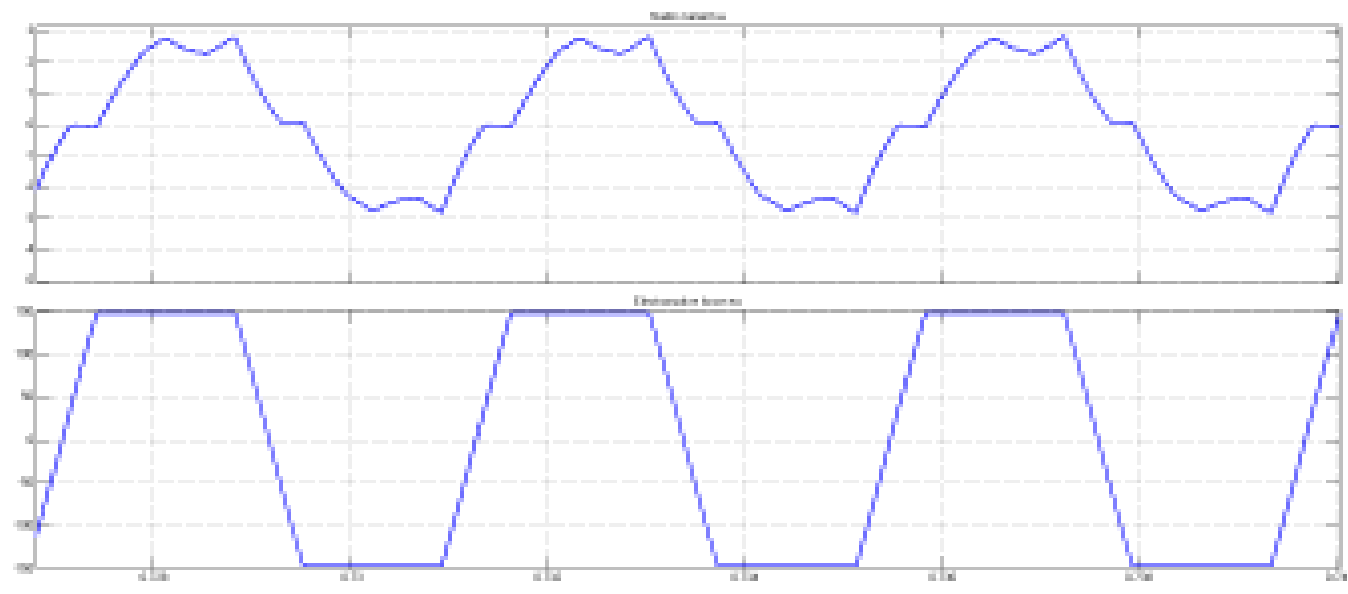

Figure 11. Presents Back EMF of Stage/Stage an at Surveyed Load Condition-utilizing Modernized Controller

Figure 12, Figure 13 shows an adjustment in position speed from 700 to $800 \mathrm{rpm}$ for no load. The advanced speed controller has quick response 25 milli seconds than Proportional Integration $80 \mathrm{~ms}$ Through altering the estimation of $\mathrm{Kp}$ and $\mathrm{Ki}$ are speed up reaction yet bring about wavering and result in prolonged the settling time.

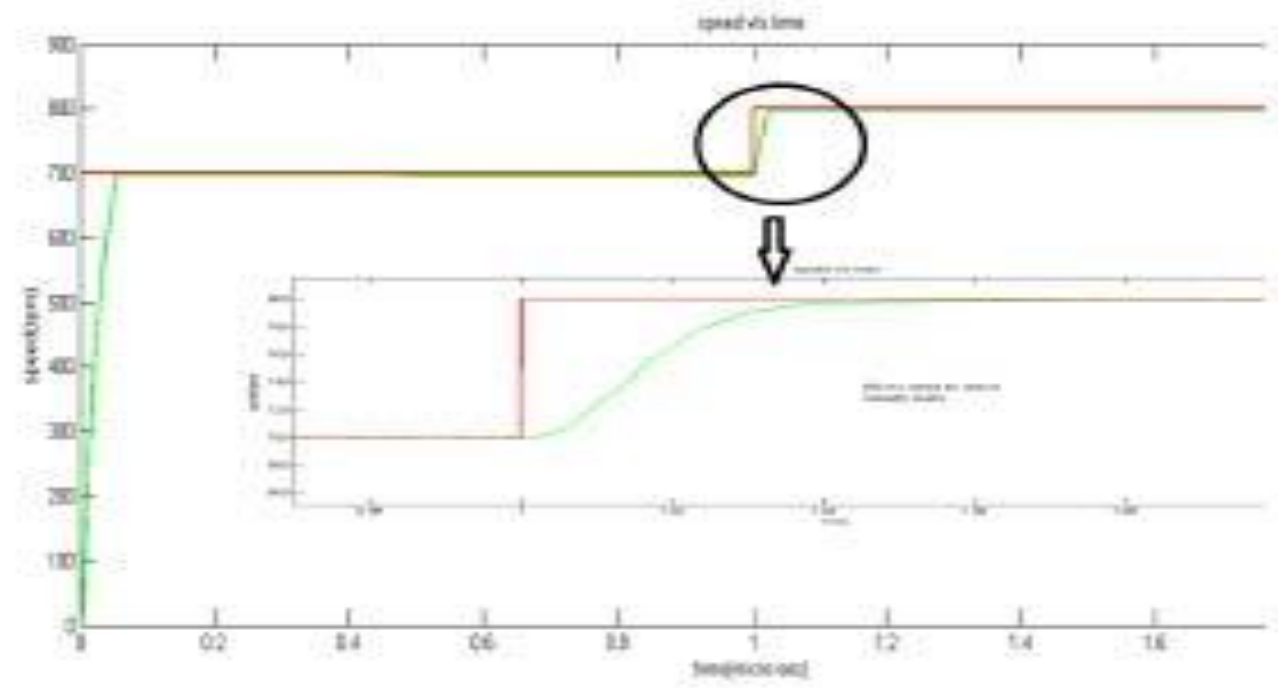

Figure 12. Speed Response of a Different Step 700 RPM to 800 RPM - Using PI Control 
Figure 14 shows the yield of both the controller in Proportional basic controller yield is limited somewhere in the range of 1000 and 50 in the computerized controller the yield is exchanged somewhere in the range of 80 and 30 .

The Simulation results are organized in Table 3. The reaction speed and less staying time, exceed time are focal points of computerized Pulse width modulation control. Minimum torque wave and improved current wave structure be able to create progressively normal torque, output effect is great execution for regular control.

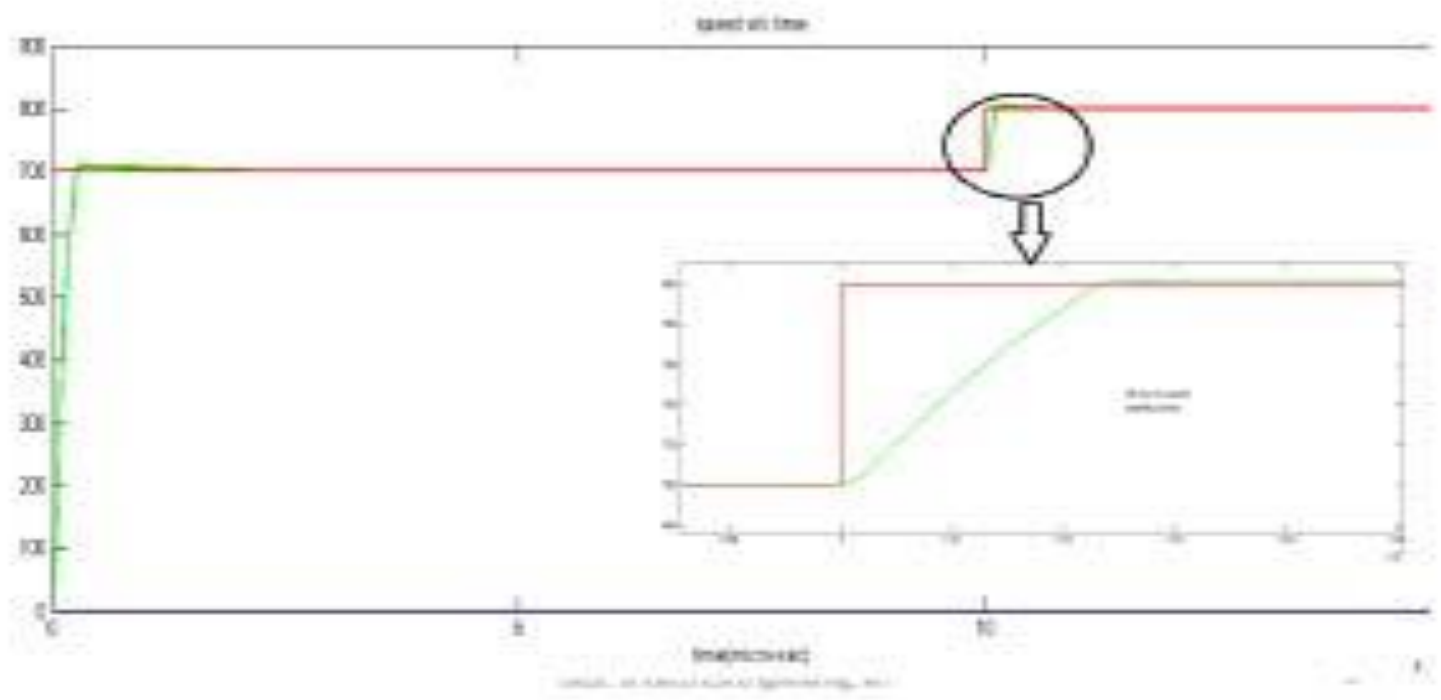

Figure 13. The Response Speed 700 RPM to 800 RPM by Using CPWM
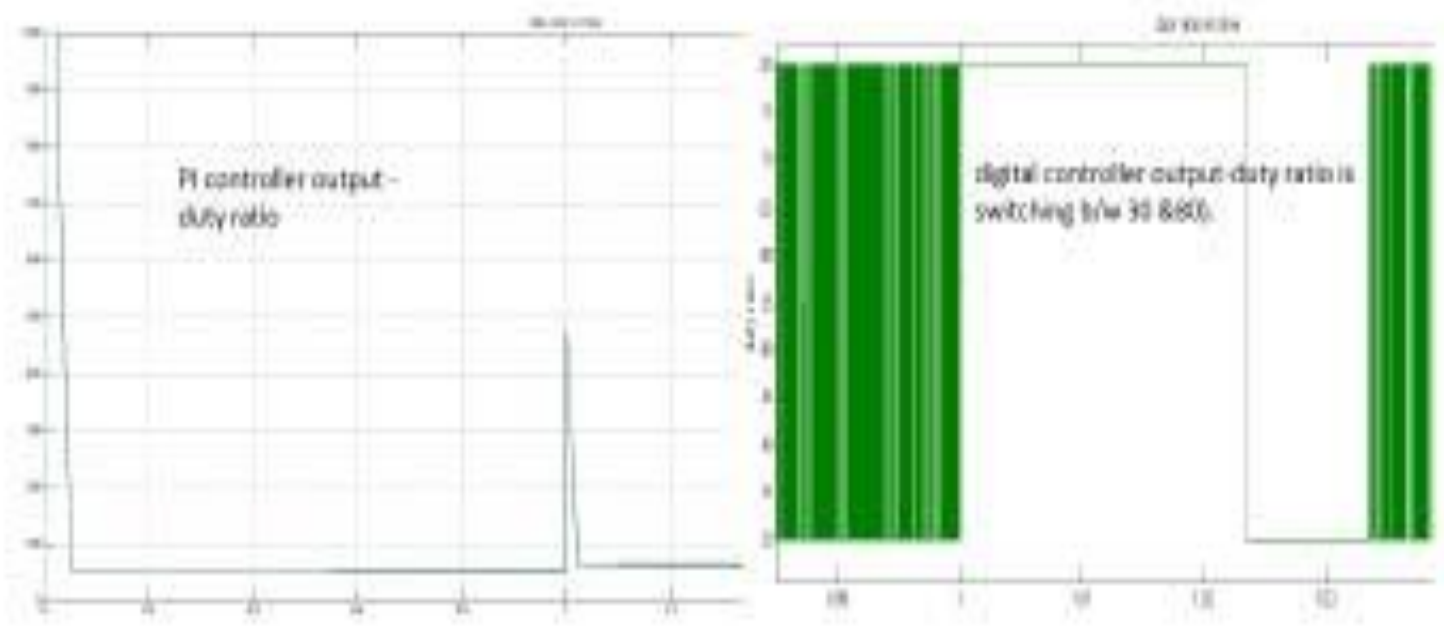

Figure 14. Output - Duty - Cycle v/s Time Response (by Simulation)

Table III. Evaluation Among Conventional \& Digital PWM Control

\begin{tabular}{llll}
\hline SL.NO & Parameters used in the simulation & Conventional control & Digital control \\
\hline 1 & Response speed & $30 \mathrm{~ms}$ & $20 \mathrm{~ms}$ \\
2 & Settling time for speed & $50 \mathrm{~ms}$ & $20 \mathrm{~ms}$ \\
3 & Waveform (CURRENT) & Near to the ideal waveform & satisfactory \\
4 & Maximum torque ripple $(\%)$ & $55.4 \%$ & $72.7 \%$ \\
\hline
\end{tabular}

Table IV.

\begin{tabular}{lllll}
\hline Sl.No & Speed (reference RPM) & Avg.Speed(RPM) & \% error & Maxi.speed (ripple in RPM) \\
\hline 1 & 700 & 710 & 1.2 & 39 \\
2 & 800 & 806 & 0.56 & 33
\end{tabular}




\begin{tabular}{lllll}
3 & 850 & 843 & 0.59 & 24 \\
4 & 900 & 890 & 2.1 & 29 \\
5 & 1000 & 1010 & 2.8 & 29 \\
6 & 1025 & 1032 & 0.32 & 39 \\
7 & 1050 & 1045 & 0.49 & 49 \\
8 & 1100 & 1097 & 0.44 & 24 \\
\hline
\end{tabular}

\section{Conclusion}

CPWM and DPWM (Digital Pulse width modulation) control arrangement maintains that deliberated their presentation examination is completed with the simulation results. The results are evaluated and validated. A Lesser Amount of speed ripple and improved current waveform can generate additional normal torque and result in a good functioning in normal management method is controlled by the set of rules like algoritham and abrupt speed reaction is the feature of the computerized PWM control technique. Wide scope of speed control is trying for computerized PWM control strategy. Because of the oversimplified idea of computerized CPWM control, it can possibly be executed in a minimal effort Application Specific Integrated Circuit (ASIC). Advanced PWM control is appropriate for applications where force/speed swell isn't critical.

\section{References}

1. Sathyan, A., Krishnamurthy, M., Milivojevic, N., \& Emadi, A. (2009). A low-cost digital control scheme for brushless DC motor drives in domestic applications. In IEEE International Electric Machines and Drives Conference, 76-82.

2. Bist, V., \& Singh, B. (2014). PFC Cuk converter-fed BLDC motor drive. IEEE Transactions on Power Electronics, 30(2), 871-887.

3. Sathyan, A., Milivojevic, N., Lee, Y.J., Krishnamurthy, M., \& Emadi, A. (2009). An FPGA-based novel digital PWM control scheme for BLDC motor drives. IEEE transactions on Industrial Electronics, 56(8), 3040-3049.

4. Nikolic, M., Kovacevic, J., Pjevalica, N., Papp, I., \& Milivojevic, N. (2013). Real time FPGA implementation of brushless DC motor control using single current sensor. In IEEE 11th International Symposium on Intelligent Systems and Informatics (SISY), 23-27.

5. Tashakori, A., Hassanudeen, M., \& Ektesabi, M. (2015). FPGA based controller drive of BLDC motor using digital PWM technique. In IEEE 11th International Conference on Power Electronics and Drive Systems, 658-662. 